\title{
Critical complications of COVID-19: A descriptive meta-analysis study
}

Kimia Vakili ${ }^{1, \dagger}$, Mobina Fathi ${ }^{1, \dagger}$, Aiyoub Pezeshgi ${ }^{2}$, Ashraf Mohamadkhani $^{3}$, Mohammadreza Hajiesmaeili ${ }^{4, *}$, Mostafa Rezaei-Tavirani ${ }^{5, *}$ and Fatemeh Sayehmiri ${ }^{1}$

${ }^{1}$ Student research committee, Faculty of Medicine, Shahid Beheshti University of Medical Sciences, 198571743, Tehran, IR Iran

${ }^{2}$ Faculty of Medicine, Zanjan University of Medical Sciences, $83153-45139$, Zanjan, IR Iran

${ }^{3}$ Digestive Disease Research Center, Tehran University of Medical Sciences, 1411713135 , Tehran, IR Iran

${ }^{4}$ Skull Base Research Center, Loghman Hakim Hospital, Shahid Beheshti University of Medical Sciences, 198571743, Tehran, IR Iran

${ }^{5}$ Proteomics Research Center, Faculty of Paramedical Sciences, Shahid Beheshti University of Medical Sciences, 198571743,

Tehran, IR Iran

*Correspondence: mrhajiesmaeili@sbmu.ac.ir (Mohammadreza Hajiesmaeili); tavirany@yahoo.com (Mostafa Rezaei-Tavirani)

$\dagger$ These authors contributed equally.

DOI: $10.31083 /$ i.rcm.2020.03.129

This is an open access article under the CC BY 4.0 license (https://creativecommons.org/licenses/by/4.0/).

The coronavirus disease 2019 (COVID-19) is a novel coronavirus infection that has rapidly spread worldwide, causing a pandemic. The main objective of this meta-analysis was to evaluate the prevalence of the most common symptoms and complications of COVID-19. All relevant studies on the clinical complications of COVID-19 have been identified by searching two web databases (i.e., PubMed and Scopus). Afterward, the relevant data were extracted from the selected studies, and then analyzed by the STATA (Version 14) random-effects model. The 30 studies selected for our meta-analysis covered 6,389 infected patients. The prevalence rates of the most common symptoms were as follows: fever: $84.30 \%(95 \% \mathrm{Cl}$ : 77.13 $\left.90.37 ; I^{2}=97.74 \%\right)$, cough: $63.01 \%(95 \% \mathrm{Cl}: 57.63-$ $\left.68.23 ;\left.\right|^{2}=93.73 \%\right)$, dyspnea: $37.16 \%(95 \% \mathrm{Cl}: 27.31-$ $\left.47.57 \% ; I^{2}=98.32 \%\right)$, fatigue: $34.22 \%(95 \% \mathrm{Cl}: 26.29$ $\left.42.62 ; I^{2}=97.29 \%\right)$, and diarrhea: $11.47 \%(95 \% \mathrm{Cl}$ : $\left.6.96-16.87 ; I^{2}=95.58 \%\right)$. Moreover, the most prevalent complications were found to be acute respiratory distress syndrome (ARDS) with 33.15\% (95\% Cl: 23.35-43.73; $\left.1^{2}=98.56 \%\right)$, arrhythmia with $16.64 \%(95 \% \mathrm{Cl}$ : 9.34$25.5 ; \mathrm{I}^{2}=92.29 \%$ ), acute cardiac injury with $15.68 \%$ (95\% Cl: $\left.11.1-20.97 ; 1^{2}=92.45 \%\right)$, heart failure with $11.50 \%\left(95 \% \mathrm{Cl}: 3.45-22.83 ; \mathrm{I}^{2}=89.48 \%\right)$, and acute kidney injury (AKI) with 9.87\% $\left(95 \% \mathrm{Cl}: 6.18-14.25 ; \mathrm{I}^{2}\right.$ $=95.64 \%)$. In this study, we assessed the prevalence of the main clinical complications of COVID-19, and found that following respiratory complications, cardiac and renal complications are the most common clinical complica- tions of COVID-19.

\section{Keywords}

COVID-19; ARDS; acute cardiac injury; acute kidney injury (AKI)

\section{Background}

Since the emergence of a cluster of pneumonia cases in Wuhan, China in December 2019, the COVID-19 disease has attracted a lot of global attention. On 9 January 2020, the Chinese Center for Disease Control and Prevention stated that the cause of this newly-emerged disease was a novel virus from the coronavirideae family, which was later named the severe acute respiratory syndrome coronavirus 2 (SARS-CoV-2), while the disease caused by this virus was then called coronavirus disease 2019 (COVID-19). Unfortunately, this epidemic was not just limited to China. On 11 March 2020, the World Health Organization (WHO) announced the COVID-19 outbreak as a pandemic (Kreutz et al., 2020; WHO, 2020b). According to WHO, as of writing this draft (8 August, 2020), about 20,000,000 individuals have been diagnosed with COVID-19, and unfortunately more than 700,000 of these patients have died (WHO, 2020a). Moreover, based on the latest reports, the most common symptoms of COVID-19 are fever, dry cough, fatigue, dyspnea, and diarrhea (Guan et al., 2020).

The main clinical complications of COVID-19 are related to the respiratory system, ranging from simple pneumonia in mild cases to acute respiratory distress syndrome (ARDS) and shock in severe patients. In this regard, the angiotensin-converting enzyme 2 (ACE2) was identified as the host cell receptor responsible for the entry of SARS-CoV-2 and the facilitation of infection. It should 


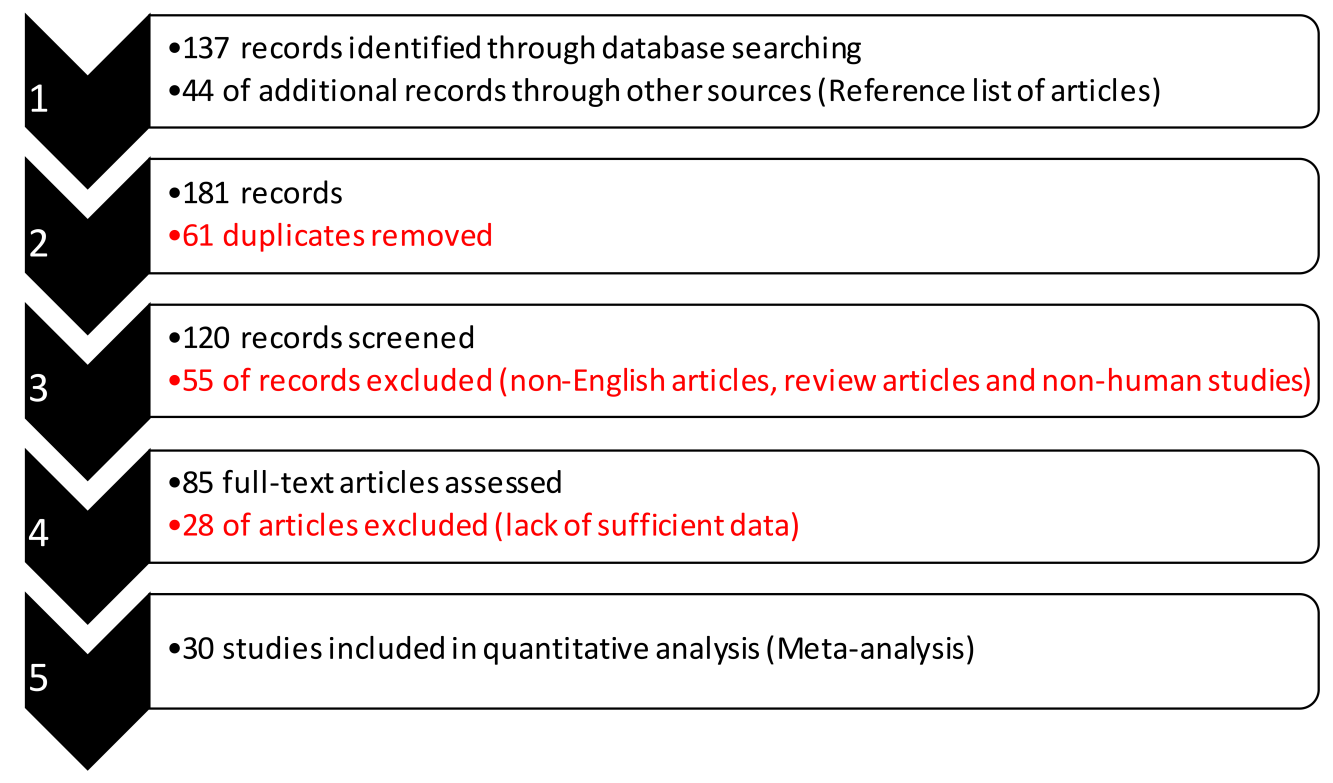

Fig. 1. Study flow diagram. To find eligible cross-sectional and case-control studies, a 5 step screening process was conducted (based on PRISMA checklist).

be noted that lung, heart, kidney, and intestine cells express ACE2.

As previously observed for SARS-CoV (Li et al., 2003), SARSCoV2 (Hoffmann et al., 2020) can similarly use ACE2 as a receptor for viral cell entrance. In the Renin-Angiotensin-Aldosterone System (RAAS), ACE2 has a catalytic effect on the conversion of angiotensin II to angiotensin 1-7, which has a number of protective effects in the cardiovascular system, and can be considered as a vasodilator. In animal experiments, the increased activity and expression of ACE2 in different organs (e.g., the heart) were associated with the administration of ARB and ACE-I (Ferrario et al., 2005; Kuster et al., 2020). Human pathogenic coronaviruses (i.e., SARS-CoV2 and SARS-CoV) may bind to their target cells through ACE2, which is expressed by the epithelial cells of the kidney, the intestine, the blood vessels, and the lung (Fang et al., 2020; Y. Wan et al., 2020). In addition, severe lung inflammation caused by SARS-CoV-2 infection can lead to dysregulation of the renin-angiotensin system as well as further development of ARDS.

In addition to respiratory manifestations, cardiovascular and renal complications may also occur following COVID-19 infection. In practice, growing evidence confirms cardiovascular involvement in the COVID-19 disease, and its negative impact on prognosis (Shi et al., 2020a). There are also some studies confirming that acute and chronic renal injuries are expected due to the high expression of ACE2 in the renal tubular epithelium (South et al., 2020).

Since these complications are extremely life-threatening, their prevalence in the clinical outcomes of patients can act as determining factors in the morbidity and mortality rates of the disease. Therefore, this paper aimed to determine the prevalence of critical complications in patients with COVID-19 through a systematic re- view of a number of recent studies and analyzing the relevant data.

\section{Methods \\ 2.1 Selection of studies}

In order to identify the eligible cross-sectional and case-control studies published on COVID-19 until May 1, 2020, we conducted a web search in the citations in PubMed. Accordingly, two authors have independently conducted the search process. In this regard, our search queries included 'ARDS AND COVID', '((Heart) OR Cardio-) AND COVID', '((Kidney) OR Renal) AND COVID', and 'Complications AND COVID'. Eligible studies were then selected based on the titles of the identified papers. In addition, the reference lists of all the related reviews (i.e., narrative and systematic) were searched to identify more related articles (Table 1 and Fig. 1).

\subsection{Inclusion and exclusion criteria}

At the first stage, all the studies analyzing the clinical complications of COVID-19 were examined. To be included in the final analysis, the screened studies must report data on the prevalence of each of the clinical complications in COVID-19 patients, including ARDS, acute heart damage, arrhythmia, heart failure, and AKI.

For all the included studies, related data, i.e., the name of the first author, date of publication, location of publication, sample size, sample age, sample gender, prevalence of symptoms (including fever, cough, dyspnea, fatigue, and diarrhea), critical complications (including ARDS, acute cardiac injury, arrhythmia, heart failure, and AKI), and clinical outcomes (e.g., mortality rate) were extracted. To avoid including conflicting results, the authors extracted data from each study separately, and then the results were compared (Table 1). 
Table 1. Baseline characteristics of studies included in this meta-analysis

\begin{tabular}{|c|c|c|c|c|c|c|c|c|c|c|c|c|c|c|}
\hline \multirow{3}{*}{$\begin{array}{l}\text { Study (ref) } \\
\text { Zhou et al., } 2020\end{array}$} & \multirow{3}{*}{$\begin{array}{l}\text { Place } \\
\text { China }\end{array}$} & \multicolumn{3}{|c|}{ Patients (No.) } & \multirow{3}{*}{$\begin{array}{c}\text { Age (Median) } \\
56\end{array}$} & \multicolumn{5}{|c|}{ Symptoms (P.) } & \multicolumn{3}{|c|}{ Complications (P.) } & \multirow{3}{*}{$\begin{array}{c}\text { Mortality (\%) } \\
28\end{array}$} \\
\hline & & All & Male & Female & & Fever & Cough & Fatigue & iarrh & yspnea & Acute Cardiac Injury & AKI & ARDS & \\
\hline & & 191 & 119 & 72 & & 94 & 79 & 23 & 5 & 29 & 17 & 15 & 54 & \\
\hline Du et al., 2020 & China & 85 & 62 & 23 & & 92 & 22 & 59 & 19 & 59 & 5 & & 47 & \\
\hline L. Wang et al., 2020 & China & 339 & 166 & 173 & 69 & 92 & 53 & 40 & 13 & 41 & 21 & 8 & 21 & 19 \\
\hline X. Li et al., 2020 & China & 25 & 10 & 15 & 73 & & & & & 92 & & & 92 & 100 \\
\hline N. Chen et al., 2020 & China & 99 & 67 & 32 & & 83 & 82 & 11 & 2 & 31 & & 3 & 17 & 11 \\
\hline D. Wang et al., 2020 & China & 138 & 75 & 63 & & 99 & 59 & 70 & 10 & 31 & 7 & 4 & 20 & 4 \\
\hline Guan et al., 2020 & China & 1099 & 637 & 459 & 47 & 44 & 68 & 38 & 4 & 19 & & 0.5 & 3 & 1 \\
\hline X. Yang et al., 2020 & China & 52 & 35 & 17 & & 98 & 77 & 12 & & 64 & & 30 & 67 & 62 \\
\hline Guo et al., 2020 & China & 187 & 91 & 96 & & & & & & & & 15 & 25 & 23 \\
\hline Y. Liu et al., 2020 & China & 12 & 8 & 4 & & 83 & 92 & 33 & 17 & & & & 50 & \\
\hline W. Liu et al., 2020 & China & 78 & 39 & 39 & 38 & & 44 & & & & & & 26 & \\
\hline Z. Li et al., 2020 & China & 193 & 95 & 98 & 57 & 89 & 69 & 39 & 18 & 36 & 12 & 28 & 28 & 66 \\
\hline T. Chen et al., 2020 & China & 274 & 171 & 103 & 62 & 91 & 68 & 50 & 28 & 44 & 44 & 11 & 72 & 41 \\
\hline J. Zhang et al., 2020 & China & 82 & 54 & 28 & 72.5 & 78 & 65 & 46 & 12 & 63 & & & 100 & \\
\hline Shi et al., 2020a & China & 416 & 205 & 211 & 64 & 80 & 35 & 13 & 4 & 28 & & 2 & 23 & 14 \\
\hline L. Wang et al., 2020 & China & 116 & 67 & 49 & 54 & & & & & & & & 10 & \\
\hline Arentz et al., 2020 & USA & 21 & 11 & & & 52 & 48 & & & 76 & & 2 & & 52 \\
\hline T. Chen et al., 2020 & China & 203 & 108 & 95 & 54 & 89 & 60 & 8 & & 2 & & & & 13 \\
\hline G. Zhang et al., 2020 & China & 221 & 108 & 113 & 55 & 91 & 61 & 71 & 11 & 29 & 8 & 5 & 22 & 5 \\
\hline Cao et al., 2020 & China & 102 & 53 & 49 & 54 & 81 & 49 & 55 & 11 & 34 & 15 & 20 & 20 & 17 \\
\hline Hu et al., 2020 & China & 323 & 166 & 157 & 61 & 84 & 51 & & & 4 & 7 & 5 & 4 & \\
\hline Huang et al., 2020 & China & 41 & 30 & 11 & 49 & 98 & 76 & 44 & 3 & 55 & 12 & 0.7 & 29 & 15 \\
\hline X. C. Li et al., 2020 & China & 548 & 279 & 269 & 60 & 95 & 76 & 47 & 33 & 57 & 22 & 17 & 38 & 17 \\
\hline Lian et al., 2020 & China & 136 & 58 & 78 & & 85 & 63 & 18 & & 13 & & 2 & 17 & 0 \\
\hline Lian et al., 2020 & China & 652 & 349 & 303 & & 80 & 65 & 18 & & 3 & & 2 & 5 & 0 \\
\hline S. Wan et al., 2020 & China & 135 & 72 & 63 & 47 & 89 & 77 & 33 & 13 & 13 & 7 & 4 & 16 & 0.7 \\
\hline Deng et al., 2020 & China & 112 & 57 & 55 & 65 & 88 & 71 & & & 56 & 13 & & & 0 \\
\hline Shao et al., 2020 & China & 136 & 90 & 46 & & 38 & 52 & 49 & 20 & 75 & & & & 0 \\
\hline Tu et al., 2020 & China & 25 & 19 & 6 & 70 & & & & & & 72 & 76 & 92 & 100 \\
\hline Tu et al., 2020 & China & 149 & 60 & 89 & 51 & & & & & & 5 & 5 & 5 & 0 \\
\hline F. Yang et al., 2020 & China & 91 & 49 & 43 & & & & & & & 34 & 17 & 80 & 100 \\
\hline Yao et al., 2020 & China & 108 & 43 & 65 & 52 & 74 & 78 & 26 & 8 & 14 & 7 & 15 & 42 & 11 \\
\hline
\end{tabular}

*Abbreviations: No = Number; $\mathrm{P}=$ prevalence.

\subsection{Statistical analysis}

The prevalence of cardiovascular and renal complications was considered as the effect size in this study. Moreover, using the binomial distribution, its variance was assessed (with 95\% confidence interval). Average weight was then applied to combine the prevalence rates from different studies. Afterward, an inverse relationship was found between the study weight and its variance. The $\mathrm{Q}$ statistic and the $\mathrm{I}^{2}$ index with a significance level of less than $10 \%$ were employed to investigate the heterogeneity of the data. Once the studies were found to be heterogeneous, the meta-analysis (random effects model) was applied. For the data analysis, the STATA software (version 14) was used, and the Metaprop (meta-analysis for proportion) command was then used in STATA, when $\mathrm{p}$ was close to 0 or 1 . To stabilize the variances, we applied the Freeman-Tukey Double Arcsine Transformation (Freeman and Tukey, 1950). It should be noted that in Metaprop, two variables in the format of $P=\mathrm{n} / \mathrm{N}$ have to be declared. This study was carried out under the approval of the
Ethics Committee of Shahid Beheshti University of Medical Sciences (IR.SBMU.RETECH.REC.1399.083).

\section{Results}

\subsection{Selection of studies}

In order to perform the analysis, we used the PRISMA checklist (Liberati et al., 2009). Initially, 137 studies were identified through database searches, and 44 additional studies were also included through other sources (e.g., the reference list of review articles). Of these 181 studies, 61 studies were excluded due to duplication. After screening the abstracts, 55 other articles were excluded as well (based on exclusion criteria, listed in the Methods Section, e.g., non-English articles, review articles, and non-human studies). Therefore, the full-text of 85 remaining studies were evaluated, and 28 other studies were excluded due to various reasons (e.g., lack of sufficient data). After carefully reviewing the selected studies, 30 published articles carried out from February, 2020 to April, 2020 were included for further analyses (Fig. 1 and Table 1). 


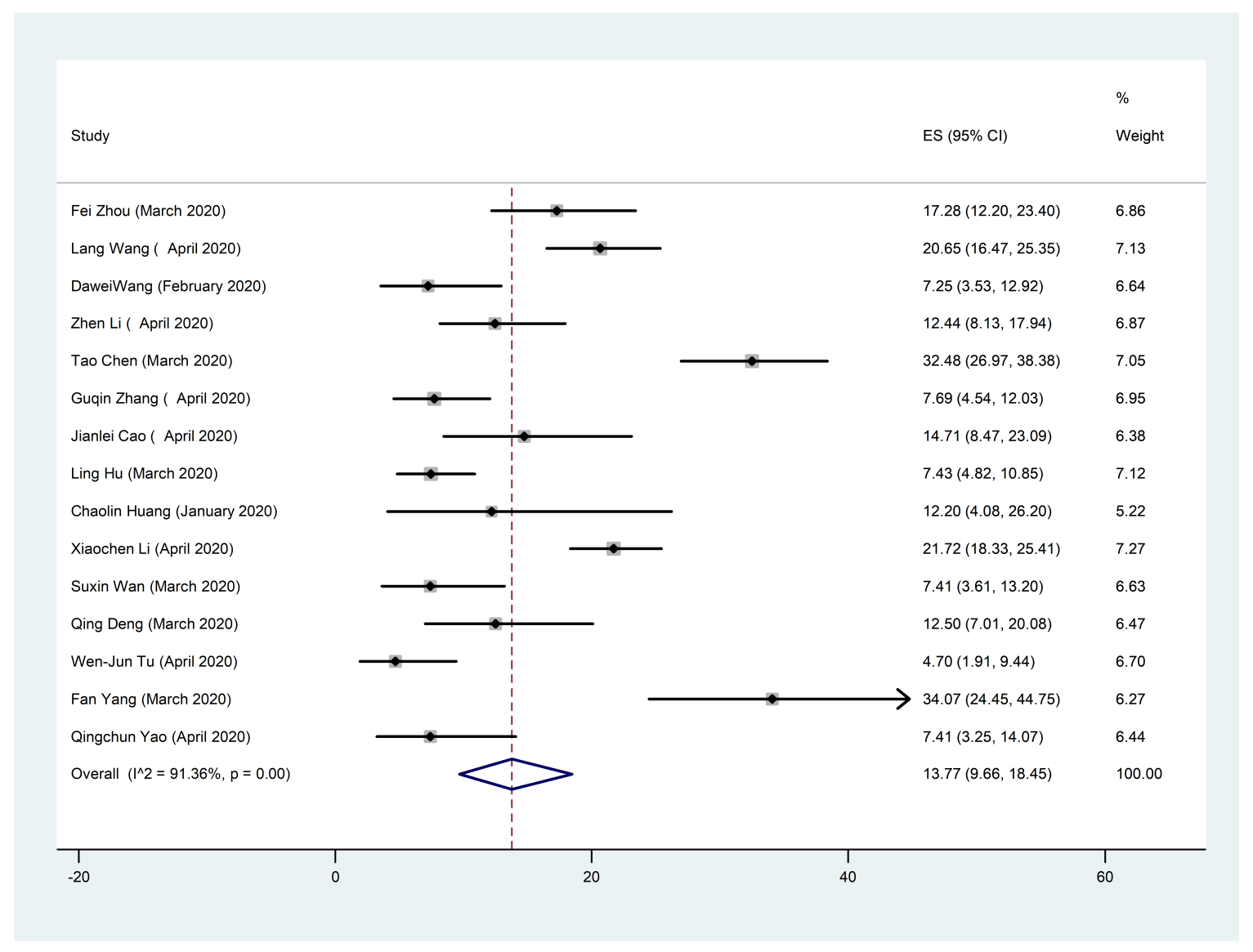

Fig. 2. Forest Plot of the prevalence of acute cardiac injury in COVID-19 patients. Each square shows effect estimate of individual studies with their $95 \%$ CI. Size of squares is proportional to the weight of each study in the meta-analysis. In this plot, studies are shown in the order of publication date and first author's names (based on a random effects model).

\subsection{Demographic characteristics of the included studies}

Pooling all the extracted data together, the total number of COVID-19 positive patients was 6,389 , including 1,402 patients with ARDS, 494 patients with acute cardiac injury, and 418 patients with AKI. The selected studies have been primarily conducted in China, except for one, which was carried out in the United States. According to the average value calculated from the articles reporting the median age of the subjects, the mean age of the patients was 57.64 years, while $45.29 \%$ of the patients were female (95\% CI: $42.61 \%$ to $47.99 \%$; $\mathrm{I}^{2}=74.56 \%$ ).

\subsection{Clinical manifestations}

Our meta-analysis revealed that the most common symptoms of COVID-19 were fever: $84.30 \%$ (95\% CI: 77.13-90.37; $\mathrm{I}^{2}=$ 97.74\%), cough: $63.01 \%$ (95\% CI: 57.63-68.23; $\mathrm{I}^{2}=93.73 \%$ ), dyspnea: $37.16 \%$ (95\% CI: $27.31-47.57 \%$; $\mathrm{I}^{2}=98.32 \%$ ), fatigue: $34.22 \%$ (95\% CI: 26.29-42.62; $\left.\mathrm{I}^{2}=97.29 \%\right)$, and diarrhea: $11.47 \%$ (95\% CI: 6.96-16.87; $\mathrm{I}^{2}=95.58 \%$ ).

\subsection{Complications}

Cardiac and renal complications were also assessed in these patients. In addition, the most common respiratory complication was ARDS with $33.15 \%$ (95\% CI: $23.35-43.73 ; \mathrm{I}^{2}=98.56 \%$ ). The prevalence rates of arrhythmia, acute cardiac injury, and heart failure were $16.64 \%$ (95\% CI: 9.34-25.5; $\left.\mathrm{I}^{2}=92.29 \%\right), 15.68 \%(95 \%$
CI: $11.1-20.97 ; \mathrm{I}^{2}=92.45 \%$ ), and $11.50 \%$ (95\% CI: 3.45-22.83; $\mathrm{I}^{2}$ $=89.48 \%$ ), respectively. Unfortunately, few related studies were available that analyzed the prevalence rates of arrhythmia and heart failure. Furthermore, the primary analysis of AKI showed a prevalence rate of $9.87 \%$ (95\% CI: 6.18-14.25; $\mathrm{I}^{2}=95.64 \%$ ) (Table 2).

\subsection{Outcomes}

Based on the primary analysis, the mortality rate was calculated as $21.70 \%$ (95\% CI: $12.39-32.70 ; \mathrm{I}^{2}=98.81 \%$ ); however, after the elimination of three of the included studies, which were only conducted on deceased patients, the total mortality rate reduced to $12.29 \%$ (95\% CI: 6.20-19.99; $\mathrm{I}^{2}=98.29 \%$ ). Moreover, we conducted a subgroup analysis to determine the mortality rate by location. As noted earlier, the included articles were mainly performed in China, with a mortality rate of $11.20 \%$ (95\% CI: 5.36$18.75 ; \mathrm{I}^{2}=98.34 \%$ ), and only one was conducted in the USA, with a mortality rate of $52.38 \%$ (95\% CI: 29.78-74.29).

\subsection{Sensitivity analysis}

According to the primary analysis, the prevalence of acute cardiac injury was $15.68 \%$ (95\% CI: $11.1-20.97 ; \mathrm{I}^{2}=92.45 \%$ ); however, after the elimination of part of the data from the Wen-Jun Tu study, and conducting sensitivity analysis (eliminating outlier data), the prevalence rate reduced to $13.77 \%$ (95\% CI: 9.66-18.45; $\mathrm{I}^{2}=91.36 \%$ ) (Fig. 2). Furthermore, the primary analysis of AKI 


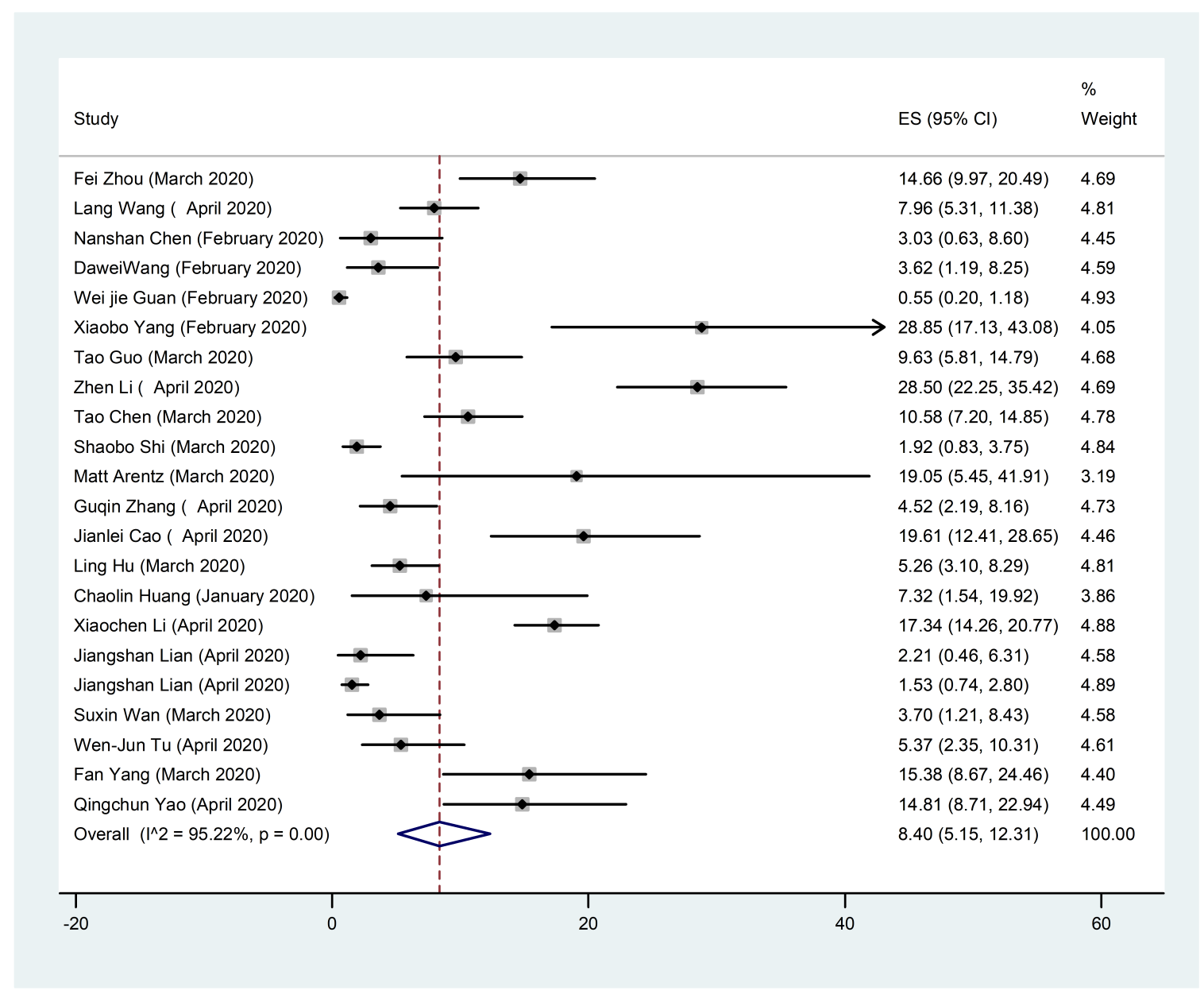

Fig. 3. Forest Plot of the prevalence of acute kidney injury (AKI) in COVID-19 patients. Each square shows effect estimate of individual studies with their $95 \%$ CI. Size of squares is proportional to the weight of each study in the meta-analysis. In this plot, studies are shown in the order of publication date and first author's names (based on a random effects model).

showed a prevalence rate of $9.87 \%\left(95 \%\right.$ CI: $6.18-14.25 ; \mathrm{I}^{2}=$ 95.64\%); however, after eliminating part of the data from WenJun Tu study, and conducting the sensitivity analysis (eliminating outlier data), this prevalence rate decreased to $8.40 \%$ (95\% CI: 5.15-12.31; $\mathrm{I}^{2}=95.22 \%$ ) (Fig. 3).

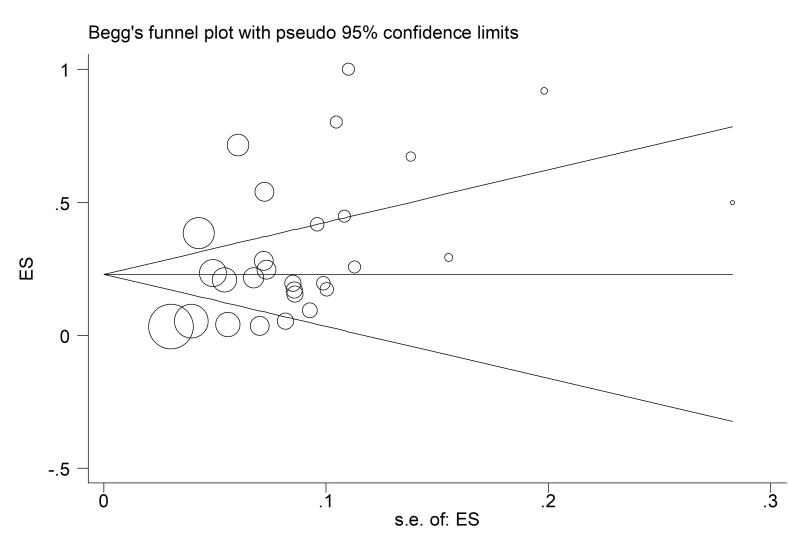

Fig. 4. Begg's funnel plot for publication bias.

\subsection{Publication bias}

Fig. 4. shows the Begg's funnel plot for the studies related to cardiac and renal injuries in COVID-19 patients. The interpretation of this plot showed no sign of publication bias in the included studies $(P=0.08)$. Accordingly, this result implies that reports have been published with both positive and negative results (Fig. 4).

\section{Discussion}

Since late 2019, a novel coronavirus outbreak, i.e., coronavirus disease 2019 (COVID-19), has emerged and spread around the world (Ghebreyesus, 2020). The city of Wuhan in China was the first infected area and the starting point of this pandemic (J. Li and $\mathrm{Xu}, 2020)$. It is noteworthy that COVID-19 is highly transmittable and has great ability to infect a cluster of cases (Chan et al., 2020).

Earlier in the pandemic, many patients did not have outpatient testing and diagnosis; therefore, they presented late and had the diagnosis made in the hospital (McCullough and Arunthamakun, 2020).

To date, no definite treatment has been discovered for COVID19. The current recommendations regarding this disease include a number o reduce the risk of infection (N. Chen et al., 2020; W. 
Table 2. Statistical analysis of reviewed studies

\begin{tabular}{|c|c|c|c|c|c|}
\hline & Number of study & Prevalence $(\%)$ & $95 \% \mathrm{CI}$ & $\mathrm{I}^{2}(\%)$ & $P$ Value for heterogeneity \\
\hline Mortality & 22 & 12.29 & $(6.20-19.99)$ & 98.29 & 0.00 \\
\hline Mortality in China & 21 & 11.20 & $(5.36-18.75)$ & 98.34 & 0.00 \\
\hline Mortality in USA & 1 & 52.38 & $(29.78-74.29)$ & & \\
\hline \multicolumn{6}{|l|}{ Gender } \\
\hline Female & 29 & 45.29 & $(42.61-47.99)$ & 74.56 & 0.00 \\
\hline Male & 29 & 54.72 & $(52.04-57.39)$ & 74.33 & 0.00 \\
\hline \multicolumn{6}{|c|}{ Clinical Manifestations } \\
\hline Fever & 24 & 84.30 & $(77.13-90.37)$ & 97.74 & 0.00 \\
\hline Cough & 25 & 63.01 & $(57.63-68.23)$ & 93.73 & 0.00 \\
\hline Dyspnea & 23 & 37.16 & $(27.31-47.57)$ & 98.32 & 0.00 \\
\hline Fatigue & 21 & 34.22 & $(26.29-42.62)$ & 97.29 & 0.00 \\
\hline Diarrhea & 18 & 11.47 & $(6.96-16.87)$ & 95.58 & 0.00 \\
\hline \multicolumn{6}{|l|}{ Complications } \\
\hline \multicolumn{6}{|l|}{ Respiratory } \\
\hline ARDS & 27 & 33.15 & $(23.35-43.73)$ & 98.56 & 0.00 \\
\hline \multicolumn{6}{|l|}{ Cardiovascular } \\
\hline Acute Cardiac injury & 15 & 15.68 & $(11.01-20.97)$ & 91.36 & 0.00 \\
\hline Arrhythmia & 5 & 16.64 & $(9.34-25.50)$ & 92.29 & 0.00 \\
\hline Heart failure & 4 & 11.50 & $(3.45-22.83)$ & 89.48 & 0.00 \\
\hline \multicolumn{6}{|l|}{ Renal } \\
\hline AKI & 21 & 9.87 & $(6.18-14.25)$ & 95.64 & 0.00 \\
\hline
\end{tabular}

Liu et al., 2020).

It has been shown that home treatment for COVID-19 immediately following the onset of symptoms is likely to significantly reduce hospitalizations, critical complications, and death (McCullough et al., 2020). Unfortunately, in severe cases of COVID-19, the disease can cause acute respiratory distress syndrome (ARDS), which is one of the deadliest complications of COVID-19, and can consequently contribute to death. According to Tian et al. (Tian et al., 2020), the prevalence rate of severe and mild outcomes was $18 \%$ of severe cases, while the remaining $82 \%$ were common cases (i.e., mild cases (73.3\%), non-pneumonia cases (4.2\%), and asymptomatic cases $(5.0 \%)$ ).

Based on very recent evidence, SARS-CoV-2 reactivation is also possible. Many factors can affect this viral reactivation, including virologic factors and immunosuppressive therapies. Virologic factors include SARS-CoV-2 genotype and viral load. Viral load can also determine disease severity and treatment response (Zou et al., 2020). Immunosuppressive agents, as commonly used agents, can generally inhibit immune functions in different ways. For instance, steroids can suppress interleukin production and lead to impaired cell-mediated immunity (Löwenberg et al., 2007). Therefore, immunosuppressive agents can be considered as a potential predisposing factor for SARS-CoV-2 reactivation (Ye et al., 2020). However, as these findings are limited to a group of 3 patients, further studies are highly recommended on the mechanism of SARS-CoV-2.

Our meta-analysis was conducted on data extracted from 30 previously published studies. These studies collected data from laboratory-confirmed COVID-19 patients, and they were mainly conducted in hospitals in China. According to previous reports during SARS-CoV and MERS-CoV outbreaks, these coro- naviruses have been shown to affect men in higher numbers than women (Badawi and Ryoo, 2016; Channappanavar et al., 2017). Moreover, regarding COVID-19, J. Yang et al. (2020) revealed that men were at a greater risk compared to women. The results of our study also confirm findings that indicate SARS-CoV2 has a higher risk in men $\left(54.72 \%\right.$ (95\% CI: 52.04-57.39; $\mathrm{I}^{2}=$ $74.33 \%)$ ) compared to women (45.29\% (95\% CI: 42.61-47.99; $\mathrm{I}^{2}=$ $74.56 \%)$ ). This difference could have resulted from stronger innate immune responses in women (Jaillon et al., 2019), and more harmful lifestyle habits (e.g., smoking) in men (Zheng et al., 2020), as well as a greater exposure to occupational hazards (e.g., Hunan wet market in China) (Huang et al., 2020). According to the age-based analysis, the mean age of subjects was $\mathbf{5 7 . 6 4}$ years, which is close to the number reported in previous studies (Rodriguez-Morales et al., 2020). Elderly patients have been shown to be at a greater risk of more serious complications and further death cases, which may be related to a higher prevalence of comorbidities in elderlies ( $\mathrm{J}$. J. Zhang et al., 2020) or their weakened immune system (Zheng et al., 2020).

We also extracted data on the most frequent symptoms of COVID-19. According to our analysis, fever with $84.30 \%$ (95\% CI: $\left.77.13-90.37 ; I^{2}=97.74 \%\right)$, cough with $63.01 \%$ (95\% CI: 57.63-68.23; $\mathrm{I}^{2}=93.73 \%$ ), dyspnea with $37.16 \%$ (95\% CI: 27.31 $47.57 \% ; \mathrm{I}^{2}=98.32 \%$ ), fatigue with $34.22 \%$ (95\% CI: 26.29-42.62; $\mathrm{I}^{2}=97.29 \%$ ), and diarrhea with $11.47 \%$ (95\% CI: 6.96-16.87; $\left.\mathrm{I}^{2}=95.58 \%\right)$ are the most prevalent symptoms of COVID-19. These results are almost identical to those of the previous reports (Rodriguez-Morales et al., 2020; J. Yang et al., 2020).

As we looked at the included studies, we realized that the most reported complication was ARDS, which had a33.15\% prevalence rate (95\% CI: $23.35-43.73 ; \mathrm{I}^{2}=98.56 \%$ ). ARDS occurs as a re- 
sult of the accumulation of fluids in alveoli, and these fluids prevent the lungs from receiving enough air. Accordingly, the cause of this phenomenon is the leakage of fluid from capillaries into the alveoli due to their damaged walls (MayoClinic, 2018). This high prevalence of ARDS is justifiable in terms of the pneumonia caused by this virus. Among the other non-respiratory outcomes, acute cardiac injury and AKI were the highest reported. Acute myocardial injury and its complications were observed in 9.5\% of all terminally-ill COVID-19 patients in Italy (as of April 13, 2020) (Sanità, 2020). According to our analyses, the prevalence rate of acute cardiac injury was $13.77 \%$ (95\% CI: $9.66 \%$ to $\left.18.45 \% ; \mathrm{I}^{2}=91.36 \%\right)$. Moreover, this complication has signs and symptoms similar to COVID-19 respiratory complications, and it may develop at any stage of this disease.

As it has already been proved that respiratory tract infections are associated with a high risk of vascular diseases (e.g., artery and venous thrombosis), clotting changes and further thrombosis are also predictable in SARS-CoV-2. According to previous reports, $10 \%$ of patients with pneumonia may experience a myocardial infarction (MI) and ischemic stroke (less frequent) (Cangemi et al., 2014; Violi et al., 2020). In addition, several studies have reported that the elevation of troponin level in COVID-19 patients is associated with poor outcomes (Lippi et al., 2020). This elevated troponin level may have different meanings in COVID-19 patients (Zimmermann et al., 2015), including pulmonary embolism (PE), type 1 and 2 MI, myocarditis, non-specific myocardial injury, and impaired renal function (Thygesen et al., 2018). It seems that elevated natriuretic peptide level is a non-specific sign, and thrombosis must be considered in an appropriate clinical context (Bikdeli et al., 2020). On the other hand, deep vein thrombosis (DVT) has not been reported yet. In addition to pneumonia, sepsis can also lead to systemic coagulation abnormalities, e.g., clotting activation and anticoagulant inhibition (Violi et al., 2020). The pathogenesis of hypercoagulability in COVID-19 is not yet identified (Singhania et al., 2020).

Acute myocardial injuries in patients with COVID-19 include arrhythmias, heart failure, cardiac arrest, acute coronary syndromes, cardiomyopathy, myocarditis, cardiogenic shock, pericarditis, and pericardial effusion (NICE, 2020). In our analysis, the prevalence rate of arrhythmia was estimated at $16.64 \%(95 \%$ CI: 9.34-25.5; $\mathrm{I}^{2}=92.29 \%$ ), while that of heart failure was $11.50 \%$ (95\% CI: $3.45-22.83$; $\mathrm{I}^{2}=89.48 \%$ ); however, due to the insufficient number of included articles and lack of sufficient data, the real numbers may be overestimated. It should be noted that symptoms related to acute cardiac injury are dyspnea, severe fatigue, chest pain, and palpitation.

Markers that can be useful in the diagnosis of an acute myocardial injury include high sensitivity troponin I (hs-cTnI) or T (hs-cTnT), and NT-proBNP. In this regard, performing an electrocardiogram (ECG) can also be helpful as ECG changes show myocardial ischemia. Moreover, the troponin level has diagnostic value as inflammatory responses of the heart to severe illness can lead to elevated troponin levels (NICE, 2020). In addition, the prevalence rate of AKI was $8.40 \%$ (95\% CI: 5.15-12.31; $\mathrm{I}^{2}=$ $95.22 \%$ ). AKI is described as a sudden failure in kidney function, which includes both structural damage (injury) and loss of function (failure). Markers that can help with AKI diagnosis in- clude serum creatinine ( $\mathrm{sCr}$ ) and/or urine output (UO) (Makris and Spanou, 2016).

Acute cellular injury due to SARS-CoV-2 fibroblast, pericytes, or cardiomyocyte infection via ACE2-mediated entry, and thus viral replication is still a theory and has not been proven yet. Analyzing histological samples has shown the direct viral infection of the conductive heart cells and myocardium with SARS-CoV-1 (Clerkin et al., 2020; Zhao et al., 2001; Zhou et al., 1982). Previous experiences of acute myocarditis with the substitute viruses indicate that direct cell damage is associated with the combination of cardiotropic viral entry into the myocytes and delayed innate immune responses which may cause diffused or focal myocardial necrosis (Cooper Jr, 2009). A few days into this direct cellular damage, necrosis and edema may cause clinical symptoms and contractile dysfunction (Cooper Jr, 2009). If correct in COVID-19, these secondary damages can suddenly manifest as clinical symptoms after a few days of persistence (Hendren et al., 2020).

Cardiovascular comorbidities are often seen among hospitalized patients, and they are related to an increase in cardiovascular outcomes and mortality rates. Recent clinical studies on COVID19 demonstrate that about $33 \%$ of the hospitalized COVID-19 patients have at least one comorbidity, e.g., diabetes (20\%), hypertension $(15 \%)$, or cardiovascular disease $(15 \%)$. All these underlying diseases had an association with an increase in the mortality rate $(7.3 \%, 6 \%$, and $10.5 \%$, respectively) (N. Chen et al., 2020; Madjid et al., 2020). Common cardiac outcomes reported in COVID-19 patients due to treatment side-effects or myocardial injury include arrhythmias, myocarditis, and acute coronary syndromes. Patients with cardiovascular injury, i.e., those with an increased troponin level, have a higher mortality rate and prevalence of ARDS (Monsuez, 2020; Shi et al., 2020b).

As noted earlier, the main focus of this study was to determine the most frequent respiratory and non-respiratory complications in COVID-19 patients, which can help in identifying the causes of the worst outcomes and death in these patients. On March 3, 2020, the mortality rate of COVID-19 was reported as $3.4 \%$ by World Health Organization (WHO) (WHO, 2020c), while according to our analysis, the mortality rate was $12.29 \%$ (95\% CI: 6.20-19.99; $\mathrm{I}^{2}=98.29 \%$ ); this number was calculated after eliminating the studies that only included deceased patients. It should be noted that the majority of the included articles were conducted on severe cases; therefore, this higher mortality rate is reasonable. We also performed a subgroup analysis to determine the mortality rate based on the location in which the results were obtained, indicating $11.20 \%$ (95\% CI: 5.36-18.75; $\mathrm{I}^{2}=98.34 \%$ ) in China and $52.38 \%$ (95\% CI: 29.78-74.29) in the USA. These results overestimate the mortality rate of patients with COVID-19 both due to the inclusion of predominantly severe cases and the lack of sufficient studies with useful data. Since no systematic review and meta-analysis has so far been published on the non-respiratory outcomes of COVID19, we anticipate that the current study have useful results for the medical community.

\section{Conclusions}

COVID-19 infection has a high morbidity rate, especially in elderly patients. These severely-ill patients require supportive medical care, which can place a huge burden on the healthcare system in different countries. There are several complications that can 
put these patients in critical conditions. The most frequent clinical outcome of COVID-19 involves respiratory complications, in particular ARDS. There are also a number of non-respiratory outcomes in COVID-19 patients. Accordingly, while these outcomes are less common compared to respiratory outcomes, they can have fatal effects on patients. Two of the most frequent non-respiratory complications in COVID-19 patients are acute cardiac injury and AKI. This information gives clinicians a better insight into what they are fighting. Since these data are being updated on a daily basis, further evaluation of these clinical outcomes is recommended.

\section{Authors' contributions}

K.V. and M.F. conceived of the presented idea, searched electronic databases and collected the data. K.V. wrote the manuscript. F.S. performed the computation and analytical methods. M.H. and M.R supervised the findings of this work. F.S., A.M., M.H. and A.P. critically revised the manuscript. All authors discussed the results and contributed to the final manuscript.

\section{Ethics approval and consent to participate}

This study was carried out under the approval of ethics committee of Shahid Beheshti University of Medical Sciences (IR.SBMU.RETECH.REC.1399.083).

\section{Acknowledgements}

The authors are grateful to Shahid Beheshti University of Medical Sciences, Tehran, IR Iran for their collaborative efforts.

\section{Availability of Data and Materials}

All data generated or analyzed during this study are included in published articles available in Table 1.

\section{Competing Interests}

The authors declare that they have no competing interests.

\section{Submitted: July 06, 2020}

Revised: September 21, 2020

Accepted: September 25, 2020

Published: September 30, 2020

\section{References}

Arentz, M., Yim, E., Klaff, L., Lokhandwala, S., Riedo, F. X., Chong, M. and Lee, M. (2020) Characteristics and outcomes of 21 critically Ill patients with COVID-19 in Washington State. JAMA 323, 1612.

Badawi, A. and Ryoo, S. G. (2016) Prevalence of comorbidities in the Middle East respiratory syndrome coronavirus (MERS-CoV): a systematic review and meta-analysis. International Journal of Infectious Diseases 49, 129-133.

Bikdeli, B., Madhavan, M. V., Jimenez, D., Chuich, T., Dreyfus, I., Driggin, E., Der Nigoghossian, C., Ageno, W., Madjid, M. and Guo, Y. (2020) COVID-19 and thrombotic or thromboembolic disease: Implications for prevention, antithrombotic therapy, and follow-up: JACC State-of-the-Art review. Journal of the American College of Cardiology $\mathbf{7 5}, 2950-2973$.

Cangemi, R., Casciaro, M., Rossi, E., Calvieri, C., Bucci, T., Calabrese, C. M., Taliani, G., Falcone, M., Palange, P. and Bertazzoni, G. (2014) Platelet activation is associated with myocardial infarction in patients with pneumonia. Journal of the American College of Cardiology 64, 1917-1925.

Cao, J., Tu, W., Cheng, W., Yu, L., Liu, Y., Hu, X. and Liu, Q. (2020) Clinical features and short-term outcomes of 102 patients with Coronavirus disease 2019 in Wuhan, China. Clinical Infectious Diseases 71, 748-755.
Chan, J. F.-W., Yuan, S., Kok, K.-H., To, K. K.-W., Chu, H., Yang, J., Xing, F., Liu, J., Yip, C. C.-Y. and Poon, R. W.-S. (2020) A familial cluster of pneumonia associated with the 2019 novel coronavirus indicating person-to-person transmission: a study of a family cluster. The Lancet $395,514-523$.

Channappanavar, R., Fett, C., Mack, M., Ten Eyck, P. P., Meyerholz, D. K. and Perlman, S. (2017) Sex-based differences in susceptibility to severe acute respiratory syndrome coronavirus infection. The Journal of Immunology 198, 4046-4053.

Chen, J., Wu, L., Zhang, J., Zhang, L., Gong, D., Zhao, Y., Hu, S., Wang, Y., Hu, X., Zheng, B., Zhang, K., Wu, H., Dong, Z., Xu, Y., Zhu, Y., Chen, X., Yu, L. and Yu, H. (2020) Deep learning-based model for detecting 2019 novel coronavirus pneumonia on high-resolution computed tomography: a prospective study. medRxiv (in press).

Chen, L., Li, X., Chen, M., Feng, Y. and Xiong, C. (2020) The ACE2 expression in human heart indicates new potential mechanism of heart injury among patients infected with SARS-CoV-2. Cardiovascular Research 116, 1097-1100.

Chen, N., Zhou, M., Dong, X., Qu, J., Gong, F., Han, Y., Qiu, Y., Wang, J., Liu, Y. and Wei, Y. (2020) Epidemiological and clinical characteristics of 99 cases of 2019 novel coronavirus pneumonia in Wuhan, China: a descriptive study. The Lancet 395, 507-513.

Chen, T., Wu, D., Chen, H., Yan, W., Yang, D., Chen, G., Ma, K., Xu, D., Yu, H. and Wang, H. (2020) Clinical characteristics of 113 deceased patients with coronavirus disease 2019: retrospective study. BMJ 368, m1091.

Clerkin, K. J., Fried, J. A., Raikhelkar, J., Sayer, G., Griffin, J. M., Masoumi, A., Jain, S. S., Burkhoff, D., Kumaraiah, D. and Rabbani, L. (2020) COVID-19 and cardiovascular disease. Circulation 141, 16481655.

Cooper Jr, L. T. (2009) Myocarditis. New England Journal of Medicine 360, 1526-1538.

Deng, Q., Hu, B., Zhang, Y., Wang, H., Zhou, X., Hu, W., Cheng, Y., Yan, J., Ping, H. and Zhou, Q. (2020) Suspected myocardial injury in patients with COVID-19: Evidence from front-line clinical observation in Wuhan, China. International Journal of Cardiology 311, 116-121.

Du, Y., Tu, L., Zhu, P., Mu, M., Wang, R., Yang, P., Wang, X., Hu, C., Ping, R., Hu, P., Li, T., Cao, F., Chang, C., Hu, Q., Jin, Y. and Xu, G. (2020) Clinical features of 85 fatal cases of COVID-19 from Wuhan. A retrospective observational study. American Journal of Respiratory and Critical Care Medicine 201, 1372-1379.

Fang, L., Karakiulakis, G. and Roth, M. (2020) Are patients with hypertension and diabetes mellitus at increased risk for COVID-19 infection? The Lancet Respiratory Medicine 8, e21.

Ferrario, C. M., Jessup, J., Chappell, M. C., Averill, D. B., Brosnihan, K. B., Tallant, E. A., Diz, D. I. and Gallagher, P. E. (2005) Effect of angiotensin-converting enzyme inhibition and angiotensin II receptor blockers on cardiac angiotensin-converting enzyme 2. Circulation 111, 2605-2610.

Freeman, M. F. and Tukey, J. W. (1950) Transformations related to the angular and the square root. The Annals of Mathematical Statistics 21, 607-611.

Ghebreyesus, T. A. (2020) WHO Director-General's opening remarks at the media briefing on COVID-19-11 March 2020. World Health Organization https://www.who.int/dg/speeches/detail/who -director-general-s-opening-remarks-atthe-media-briefing-o n-covid-19---11-march-2020

Guan, W.-j., Ni, Z.-y., Hu, Y., Liang, W.-h., Ou, C.-q., He, J.-x., Liu, L., Shan, H., Lei, C.-1. and Hui, D. S. (2020) Clinical characteristics of coronavirus disease 2019 in China. New England Journal of Medicine 382, 1708-1720.

Guo, T., Fan, Y., Chen, M., Wu, X., Zhang, L., He, T., Wang, H., Wan, J., Wang, X. and Lu, Z. (2020) Cardiovascular implications of fatal outcomes of patients with Coronavirus disease 2019 (COVID-19). JAMA Cardiology 5, 811 .

Guzik, T. J., Mohiddin, S. A., Dimarco, A., Patel, V., Savvatis, K., Marelli-Berg, F. M., Madhur, M. S., Tomaszewski, M., Maffia, P., D'Acquisto, F., Nicklin, S. A., Marian, A. J., Nosalski, R., Murray, 
E. C., Guzik, B., Berry, C., Touyz, R. M., Kreutz, R., Wang, D. W., Bhella, D., Sagliocco, O., Crea, F., Thomson, E. C. and McInnes, I. B. (2020) COVID-19 and the cardiovascular system: implications for risk assessment, diagnosis, and treatment options. Cardiovascular Research 116, 1666-1687.

Hendren, N. S., Drazner, M. H., Bozkurt, B. and Cooper, L. T. (2020) Description and proposed management of the acute COVID-19 Cardiovascular syndrome. Circulation 141, 1903-1914.

Hoffmann, M., Kleine-Weber, H., Schroeder, S., Krüger, N., Herrler, T., Erichsen, S., Schiergens, T. S., Herrler, G., Wu, N., Nitsche, A., Müller, M. A., Drosten, C. and Pöhlmann, S. (2020) SARS-CoV-2 cell entry depends on ACE2 and TMPRSS2 and is blocked by a clinically proven protease inhibitor. Cell 181, 271-280.e8.

Hu, L., Chen, S., Fu, Y., Gao, Z., Long, H., Wang, J. M., Ren, H. W., Zuo, Y., Li, H., Wang, J., Xu, Q. B., Yu, W. X., Liu, J., Shao, C., Hao, J. J., Wang, C. Z., Ma, Y., Wang, Z., Yanagihara, R. and Deng, Y. (2020) Risk factors associated with clinical outcomes in 323 COVID19 hospitalized patients in Wuhan, China. Clinical infectious diseases: an official publication of the Infectious Diseases Society of America (in press).

Huang, C., Wang, Y., Li, X., Ren, L., Zhao, J., Hu, Y., Zhang, L., Fan, G., Xu, J., Gu, X., Cheng, Z., Yu, T., Xia, J., Wei, Y., Wu, W., Xie, X., Yin, W., Li, H., Liu, M., Xiao, Y., Gao, H., Guo, L., Xie, J., Wang, G., Jiang, R., Gao, Z., Jin, Q., Wang, J. and Cao, B. (2020) Clinical features of patients infected with 2019 novel coronavirus in Wuhan, China. The Lancet 395, 497-506.

Jaillon, S., Berthenet, K. and Garlanda, C. (2019) Sexual dimorphism in innate immunity. Clinical Reviews in Allergy and Immunology 56, 308321.

Kreutz, R., Algharably, E. A. E., Azizi, M., Dobrowolski, P., Guzik, T., Januszewicz, A., Persu, A., Prejbisz, A., Riemer, T. G., Wang, J. and Burnier, M. (2020) Hypertension, the renin-angiotensin system, and the risk of lower respiratory tract infections and lung injury: implications for COVID-19European Society of Hypertension COVID-19 Task Force Review of Evidence. Cardiovascular Research 116, 16881699.

Kuster, G. M., Pfister, O., Burkard, T., Zhou, Q., Twerenbold, R., Haaf, P., Widmer, A. F. and Osswald, S. (2020) SARS-CoV2: should inhibitors of the renin-angiotensin system be withdrawn in patients with COVID19? European Heart Journal 41, 1801-1803.

Lauer, S. A., Grantz, K. H., Bi, Q., Jones, F. K., Zheng, Q., Meredith, H. R., Azman, A. S., Reich, N. G. and Lessler, J. (2020) The incubation period of coronavirus disease 2019 (COVID-19) from publicly reported confirmed cases: estimation and application. Annals of Internal Medicine 172, 577-582.

$\mathrm{Li}, \mathrm{J}$. and $\mathrm{Xu}, \mathrm{G}$. (2020) Lessons from the Experience in Wuhan to Reduce Risk of COVID-19 Infection in Patients Undergoing Long-Term Hemodialysis. Clinical Journal of the American Society of Nephrology 15, 717-719.

Li, W., Moore, M. J., Vasilieva, N., Sui, J., Wong, S. K., Berne, M. A., Somasundaran, M., Sullivan, J. L., Luzuriaga, K. and Greenough, T. C. (2003) Angiotensin-converting enzyme 2 is a functional receptor for the SARS coronavirus. Nature 426, 450-454.

Li, X., Wang, L., Yan, S., Yang, F., Xiang, L., Zhu, J., Shen, B. and Gong, Z. (2020) Clinical characteristics of 25 death cases with COVID-19: A retrospective review of medical records in a single medical center, Wuhan, China. International Journal of Infectious Diseases 94, 128132.

Li, X. C., Xu, S., Yu, M., Wang, K., Tao, Y., Zhou, Y., Shi, J., Zhou, M., Wu, B., Yang, Z., Zhang, C., Yue, J., Zhang, Z., Renz, H., Liu, X., Xie, J., Xie, M. and Zhao, J. (2020) Risk factors for severity and mortality in adult COVID-19 inpatients in Wuhan. Journal of Allergy and Clinical Immunology 146, 110-118.

Li, Z., Wu, M., Yao, J., Guo, J., Liao, X., Song, S., Li, J., Duan, G., Zhou, Y. and Wu, X. (2020) Caution on kidney dysfunctions of COVID-19 patients. medRxiv (in press).

Lian, J., Jin, X., Hao, S., Cai, H., Zhang, S., Zheng, L., Jia, H., Hu, J., Gao, J. and Zhang, Y. (2020) Analysis of Epidemiological and Clinical features in older patients with Corona Virus Disease 2019 (COVID-19) out of Wuhan. Clinical Infectious Diseases 15, 740-747.

Liberati, A., Altman, D. G., Tetzlaff, J., Mulrow, C., Gøtzsche, P. C., Ioannidis, J. P., Clarke, M., Devereaux, P. J., Kleijnen, J. and Moher, D. (2009) The PRISMA statement for reporting systematic reviews and meta-analyses of studies that evaluate health care interventions: explanation and elaboration. Annals of internal medicine 151, W-65-W-94.

Lippi, G., Lavie, C. J. and Sanchis-Gomar, F. (2020) Cardiac troponin I in patients with coronavirus disease 2019 (COVID-19): Evidence from a meta-analysis. Progress in Cardiovascular Diseases 63, 390-391.

Liu, W., Tao, Z., Wang, L., Yuan, M., Liu, K., Zhou, L., Wei, S., Deng, Y., Liu, J., Liu, H., Yang, M. and Hu, Y. (2020) Analysis of factors associated with disease outcomes in hospitalized patients with 2019 novel coronavirus disease. Chinese Medical Journal 133, 1032-1038.

Liu, Y., Yang, Y., Zhang, C., Huang, F., Wang, F., Yuan, J., Wang, Z., Li, J., Li, J. and Feng, C. (2020) Clinical and biochemical indexes from 2019$\mathrm{nCoV}$ infected patients linked to viral loads and lung injury. Science China Life Sciences 63, 364-374.

Löwenberg, M., Verhaar, A. P., van den Brink, G. R. and Hommes, D. W. (2007) Glucocorticoid signaling: a nongenomic mechanism for T-cell immunosuppression. Trends in Molecular Medicine 13, 158-163.

Madjid, M., Safavi-Naeini, P., Solomon, S. D. and Vardeny, O. (2020) Potential effects of coronaviruses on the cardiovascular system: a review. JAMA Cardiology 5, 831.

Makris, K. and Spanou, L. (2016) Acute kidney injury: Definition, pathophysiology and clinical phenotypes. The Clinical Biochemist Reviews 37, 85-98.

MayoClinic. (2018) ARDS. Available at: https://www.mayoclinic.o $\mathrm{rg} /$ diseases-conditions/ards/symptoms-causes/syc-20355576 (Accessed: March 10th, 2018).

McCullough, P. A. and Arunthamakun, J. (2020) Disconnect between community testing and hospitalization for SARS-CoV-2 (COVID-19) infection. Proceedings (Baylor University Medical Center) 33, 481.

McCullough, P. A., Kelly, R. J., Ruocco, G., Lerma, E., Tumlin, J., Wheelan, K., Katz, N., Lepor, N. E., Vijay, K. and Carter, H. (2020) Pathophysiological basis and rationale for early outpatient treatment of SARS-CoV-2 (COVID-19) Infection. Travel Medicine and Infectious Disease (in press)

Monsuez, J.-J. (2020) Cardiology practice in the COVID-19 era. European Journal of Preventive Cardiology 27, 1133-1135.

NICE. (2020) COVID-19 rapid guideline: acute myocardial injury (NICE guideline [NG171]) Available at: https://www.nice.org.uk/guid ance/ng171 (Accessed: 23 April 2020).

Rodriguez-Morales, A. J., Cardona-Ospina, J. A., Gutiérrez-Ocampo, E., Villamizar-Peña, R., Holguin-Rivera, Y., Escalera-Antezana, J. P., Alvarado-Arnez, L. E., Bonilla-Aldana, D. K., Franco-Paredes, C., Henao-Martinez, A. F., Paniz-Mondolfi, A., Lagos-Grisales, G. J., Ramírez-Vallejo, E., Suárez, J. A., Zambrano, L. I., Villamil-Gómez, W. E., Balbin-Ramon, G. J., Rabaan, A. A., Harapan, H., Dhama, K., Nishiura, H., Kataoka, H., Ahmad, T. and Sah, R. (2020) Clinical, laboratory and imaging features of COVID-19: A systematic review and meta-analysis. Travel Medicine and Infectious Disease (in press).

Sanità, I. S. D. Characteristics of SARS-CoV-2 patients dying in Italy Available at: https://www.epicentro.iss.it/en/coronavirus/bo llettino/Report-COVID-2019_13_april_2020.pdf (Accessed: April 13th , 2020).

Shao, F., Xu, S., Ma, X., Xu, Z., Lyu, J., Ng, M., Cui, H., Yu, C., Zhang, Q., Sun, P. and Tang, Z. (2020) In-hospital cardiac arrest outcomes among patients with COVID-19 pneumonia in Wuhan, China. Resuscitation 151, 18-23.

Shi, S., Qin, M., Shen, B., Cai, Y., Liu, T., Yang, F., Gong, W., Liu, X., Liang, J. and Zhao, Q. (2020a) Association of cardiac injury with mortality in hospitalized patients with COVID-19 in Wuhan, China. JAMA Cardiology 5, 802 .

Shi, S., Qin, M., Shen, B., Cai, Y., Liu, T., Yang, F., Gong, W., Liu, X., Liang, J. and Zhao, Q. (2020b) Cardiac injury in patients with corona virus disease 2019. JAMA Cardiol (in press).

Singhania, N., Bansal, S., Nimmatoori, D. P., Ejaz, A. A., McCullough, P. A. and Singhania, G. (2020) Current Overview on Hypercoagulability in COVID-19. American Journal of Cardiovascular Drugs (in press). 
South, A. M., Diz, D. and Chappell, M. C. (2020) COVID-19, ACE2 and the cardiovascular consequences. The American Journal of Physiology: Heart and Circulatory Physiology 318, H1084-H1090.

Thygesen, K., Alpert, J. S., Jaffe, A. S., Chaitman, B. R., Bax, J. J., Morrow, D. A. and White, H. D. (2018) Fourth universal definition of myocardial infarction (2018). Journal of the American College of Cardiology 72, 2231-2264.

Tian, S., Hu, N., Lou, J., Chen, K., Kang, X., Xiang, Z., Chen, H., Wang, D., Liu, N., Liu, D., Chen, G., Zhang, Y., Li, D., Li, J., Lian, H., Niu, S., Zhang, L. and Zhang, J. (2020) Characteristics of COVID-19 infection in Beijing. Journal of Infection 80, 401-406.

Tu, W., Cao, J., Yu, L., Hu, X. and Liu, Q. (2020) Clinicolaboratory study of 25 fatal cases of COVID-19 in Wuhan. Intensive Care Medicine 46, 1117-1120.

Violi, F., Pastori, D., Cangemi, R., Pignatelli, P. and Loffredo, L. (2020) Hypercoagulation and antithrombotic treatment in coronavirus 2019: a new challenge. Thrombosis and Haemostasis 120, 949.

Wan, S., Xiang, Y., Fang, W., Zheng, Y., Li, B., Hu, Y., Lang, C., Huang, D., Sun, Q., Xiong, Y., Huang, X., Lv, J., Luo, Y., Shen, L., Yang, H., Huang, G. and Yang, R. (2020) Clinical features and treatment of COVID-19 patients in northeast Chongqing. Journal of Medical Virology 92, 797-806.

Wan, Y., Graham, R., Baric, R. and Li, F. (2020) Receptor Recognition by the Novel Coronavirus from Wuhan: an Analysis Based on DecadeLong Structural Studies of SARS Coronavirus. Journal of Virology Mar 94, e00127-20.

Wang, D., Hu, B., Hu, C., Zhu, F., Liu, X., Zhang, J., Wang, B., Xiang, H., Cheng, Z. and Xiong, Y. (2020) Clinical characteristics of 138 hospitalized patients with 2019 novel coronavirus-infected pneumonia in Wuhan, China. JAMA 323, 1061-1069.

Wang, L., He, W., Yu, X., Hu, D., Bao, M., Liu, H., Zhou, J. and Jiang, H. (2020) Coronavirus disease 2019 in elderly patients: Characteristics and prognostic factors based on 4-week follow-up. Journal of Infection 80, 639-645.

Wang, L., Li, X., Chen, H., Yan, S., Li, D., Li, Y. and Gong, Z. (2020) Coronavirus disease 19 infection does not result in acute kidney injury: an analysis of 116 hospitalized patients from Wuhan, China. American Journal of Nephrology 51, 343-348.

WHO (2020a) Coronavirus disease (COVID-19) Situation Report - 201.

WHO (2020b) WHO announces COVID-19 outbreak a pandemic Available at: http://www.euro.who.int/en/health-topics/heal th-emergencies/coronavirus-covid-19/news/news/2020/3/ who-announces-covid-19-outbreak-a-pandemic (Accessed: 12 March 2020).

WHO (2020c) WHO Director-General's opening remarks at the media briefing on COVID-19 - 3 March 2020 Available at: https://www. who.int/dg/speeches/detail/who-director-general-s-opening -remarks-at-the-media-briefing-on-covid-19---3-march-2020 (Accessed: 3 March 2020).

Wu, C., Chen, X., Cai, Y., Zhou, X., Xu, S., Huang, H., Zhang, L., Zhou, X., Du, C. and Zhang, Y. (2020) Risk factors associated with acute respiratory distress syndrome and death in patients with coronavirus disease 2019 pneumonia in Wuhan, China. JAMA Internal Medicine 180, 934

Yang, F., Shi, S., Zhu, J., Shi, J., Dai, K. and Chen, X. (2020) Analysis of
92 deceased patients with COVID-19. Journal of Medical Virology (in press).

Yang, J., Zheng, Y., Gou, X., Pu, K., Chen, Z., Guo, Q., Ji, R., Wang, H., Wang, Y. and Zhou, Y. (2020) Prevalence of comorbidities and its effects in patients infected with SARS-CoV-2: a systematic review and meta-analysis. International Journal of Infectious Diseases 94, 91-95.

Yang, X., Yu, Y., Xu, J., Shu, H., Xia, J., Liu, H., Wu, Y., Zhang, L., Yu, Z., Fang, M., Yu, T., Wang, Y., Pan, S., Zou, X., Yuan, S. and Shang, Y. (2020) Clinical course and outcomes of critically ill patients with SARS-CoV-2 pneumonia in Wuhan, China: a single-centered, retrospective, observational study. The Lancet Respiratory Medicine $\mathbf{8}$, 475-481.

Yao, Q., Wang, P., Wang, X., Qie, G., Meng, M., Tong, X., Bai, X., Ding, M., Liu, W. and Liu, K. (2020) Retrospective study of risk factors for severe SARS-Cov-2 infections in hospitalized adult patients. Polish Archives of Internal Medicine (in press).

Ye, G., Pan, Z., Pan, Y., Deng, Q., Chen, L., Li, J., Li, Y. and Wang, X. (2020) Clinical characteristics of severe acute respiratory syndrome coronavirus 2 reactivation. Journal of Infection 80, e14-e17.

Zhang, G., Hu, C., Luo, L., Fang, F., Chen, Y., Li, J., Peng, Z. and Pan, H. (2020) Clinical features and outcomes of 221 patients with COVID-19 in Wuhan, China. medRxiv (in press).

Zhang, J. J., Dong, X., Cao, Y., Yuan, Y., Yang, Y., Yan, Y., Akdis, C. A. and Gao, Y. (2020) Clinical characteristics of 140 patients infected with SARS-CoV-2 in Wuhan, China. Allergy 75, 1730-1741.

Zhang, J., Wang, X., Jia, X., Li, J., Hu, K., Chen, G., Wei, J., Gong, Z., Zhou, C. and Yu, H. (2020) Risk factors for disease severity, unimprovement, and mortality of COVID-19 patients in Wuhan, China. Clinical Microbiology and Infection (in press).

Zhao, J., Zhou, G. and Sun, Y. (2001) SARS coronavirus could cause multi-organ infection. Medical Journal of Chinese People's Liberation Army

Zheng, Z., Peng, F., Xu, B., Zhao, J., Liu, H., Peng, J., Li, Q., Jiang, C., Zhou, Y., Liu, S., Ye, C., Zhang, P., Xing, Y., Guo, H. and Tang, W. (2020) Risk factors of critical \& mortal COVID-19 cases: A systematic literature review and meta-analysis. Journal of Infection 81, e16-e25.

Zhou, F., Yu, T., Du, R., Fan, G., Liu, Y., Liu, Z., Xiang, J., Wang, Y., Song, B., Gu, X., Guan, L., Wei, Y., Li, H., Wu, X., Xu, J., Tu, S., Zhang, Y., Chen, H. and Cao, B. (2020) Clinical course and risk factors for mortality of adult inpatients with COVID-19 in Wuhan, China: a retrospective cohort study. The Lancet 395, 1054-1062.

Zhou, G., Zhao, J. and Wang, S. (1982) Pathological study of impact of SARS coronavirus on heart and its conduction system in SARS patients. Medical Journal of Chinese People's Liberation Army

Zimmermann, F. M., De Bruyne, B., Pijls, N. H., Desai, M., Oldroyd, K. G., Park, S.-J., Reardon, M. J., Wendler, O., Woo, J. and Yeung, A. C. (2015) Rationale and design of the Fractional Flow Reserve Versus Angiography for Multivessel Evaluation (FAME) 3 trial: a comparison of fractional flow reserve-guided percutaneous coronary intervention and coronary artery bypass graft surgery in patients with multivessel coronary artery disease. American heart journal 170, 619-626. e612.

Zou, L., Ruan, F., Huang, M., Liang, L., Huang, H., Hong, Z., Yu, J., Kang, M., Song, Y. and Xia, J. (2020) SARS-CoV-2 viral load in upper respiratory specimens of infected patients. New England journal of medicine 382, 1177-1179. 